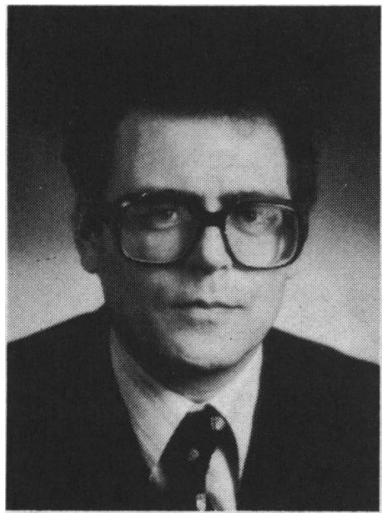

A. Hammer

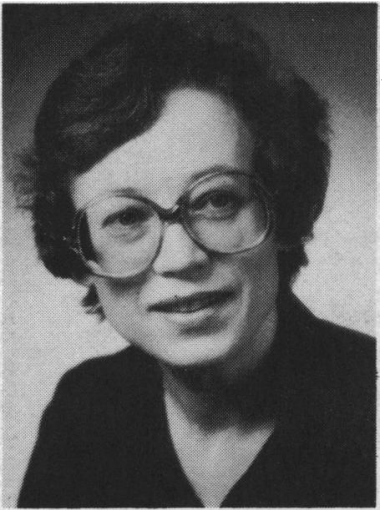

Ann-Louise Schwartzbach

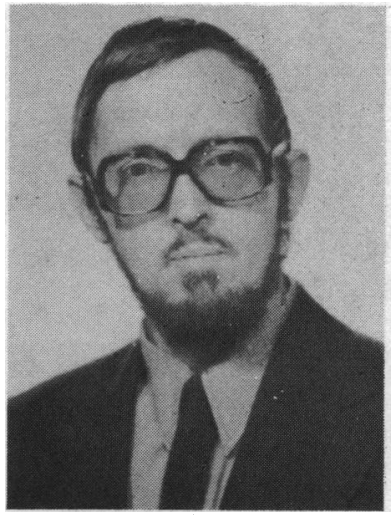

P.-E. Paulev

\title{
SOME RISK FACTORS IN TRAMPOLINING ILLUSTRATED BY SIX SERIOUS INJURIES
}

A. HAMMER, MD, Ann-Louise SCHWARTZBACH, MD and P.-E. PAULEV, MD, DSc

Glostrup University Hospital, Copenhagen, Department of Orthopaedic Surgery and Department of Neuro-Surgery and Institute of Medical Physiology B, University of Copenhagen

\section{ABSTRACT}

Four case histories out of 75 significant trampoline injuries (from a total of 198 injuries re-examined) plus two recent accidents (1979) are presented, illustrating that the trampoline is posing an undue risk of serious injury. It is argued that the only single factor capable of preventing trampoline injuries is a trampoline ban. This is imperative in schools. Trampoline clubs are advised to reconsider the risk factors involved.

\section{INTRODUCTION}

In the past serious injuries from trampoline jumping have been reported by several authors (Clarke, 1977; Ellis, Green et al, 1960; Frykman and Hilding, 1970; Hammer, Schwartzbach et al, 1981 a, b; Rapp and Nicely, 1980; Steinbrück and Paeslack, 1978).

We have analysed 75 significant injuries among 198 trampoline injuries in a preceding report in this Journal (Hammer, Schwartzbach et al, 1981 c).

The following four case histories from this study plus two accidents seen in the same hospital in 1979 (one resulting in tetraplegia) illustrate the main risk factors involved.

The large and the mini trampoline are shown in Fig. 1 and Fig. 2.

\section{Correspondence to:}

Anders Hammer and Poul-Erik Paulev,

University of Copenhagen,

Institute of Medical Physiology B,

71 Raadmandsgade,

DK-2200 Copenhagen N,

Denmark

\section{CASE REPORTS}

\section{Case 1}

This patient was an 11 year old boy. He assisted his specially qualified teacher and some other pupils in unfolding a large trampoline at his school. When the other pupils suddenly withdrew, his right arm was jammed in the frame (Fig. 3.).

The fracture was reduced and had to be re-reduced two weeks later. Three years after the accident there were no complaints and normal findings.

\section{Case 2}

A 14 year old boy assisted his coach and some other boys in unfolding a large trampoline at his club. Although he was strong and experienced, his right arm jammed in the frame when the others suddenly withdrew (Fig. 4).

The fracture was initially treated with a closed reduction but had to have an osteosynthesis on the fifth day. The plate was removed after 18 months. Two years after the accident there were no complaints and normal findings.

\section{Case 3}

This patient was a 15 year old boy. He injured himself 

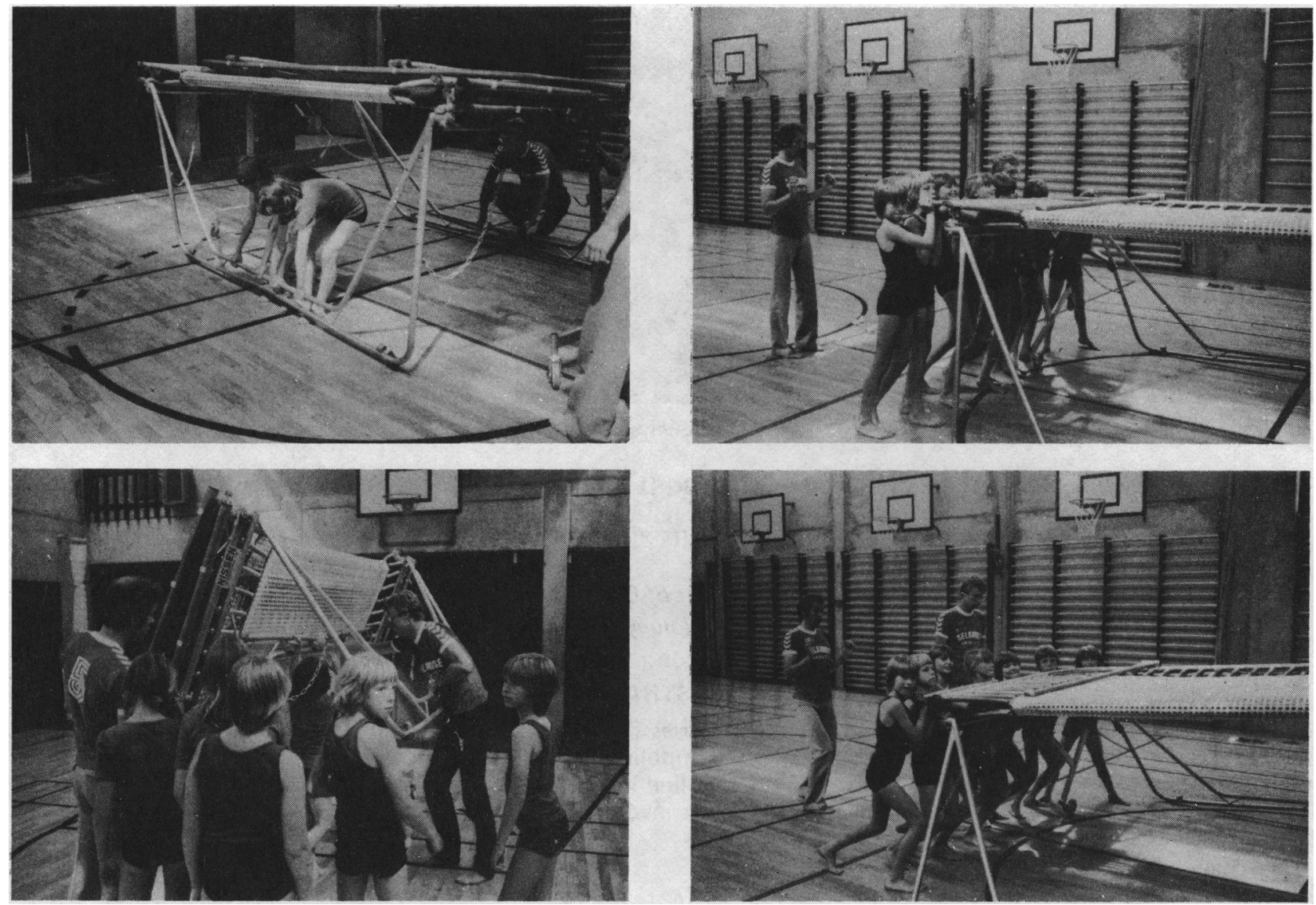

Fig. 1: Children and their specially qualified teacher unfolding the large trampoline. In our opinion children should not be allowed to handle this heavy instrument.

at school by doing a somersault from the mini trampoline. He landed on the safety mattress $(30 \mathrm{~cm}$ thick) with the left shoulder leading. The helpers including his specially qualified teacher were present. The boy dislocated his left shoulder (Fig. 5). It was reduced under general anaesthetic, but resulted in recurrent dislocation with significant limitation of function. Three years after the accident the boy was discharged from military service due to his recurrent shoulder dislocation.

\section{Case 4}

A 15 year old boy injured himself at school by attempting to somersault from a mini trampoline. His teacher and some of the other pupils were present as helpers. He landed wrongly on the mattress $(30 \mathrm{~cm}$ thick). The result was a slipped epiphysis in the right upper tibia (Fig. 6). The lesion was reduced and initially treated with traction followed by plaster of Paris. Three years after the accident the boy suffered a slightly painful knee, reasonably explained by cessation of growth in one area of the epiphyseal plate, while growth continued in the remaining area. This lead to angulation of the medial tibial plateau.

\section{Case 5}

This patient was a 12 year old boy who injured himself at his club by doing feet bounces on the large trampoline (1979). Although his coach was present and the boy himself well experienced he became afraid of the jumping height, turned a little and hit the bed of the trampoline with the right arm leading. The bed hit back. The boy suffered a fracture of the forearm (Fig. 7), treated by closed reduction. One year after the accident there were no complaints and normal findings.

\section{Case 6}

This patient was an 18 year old boy with eight years of trampoline experience from both types. He injured himself at his club by doing a forward somersault from a mini trampoline (1979). Although his coach and other helpers were present he landed on the safety mattress 


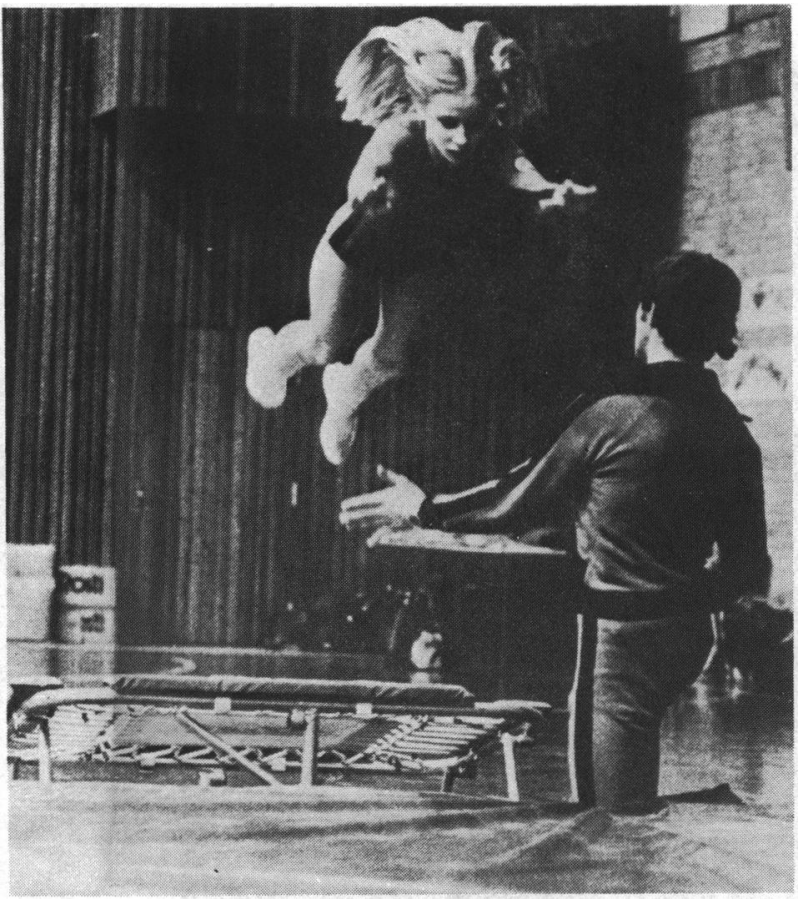

Fig. 2: A girl jumping from the mini trampoline before landing on the "safety" mattress. This photograph shows no children acting as helpers. In our opinion children should not be allowed to act as helpers because of the nasty after-effect they are going to experience when the accident occurs and leave some of them with a guilty conscience.

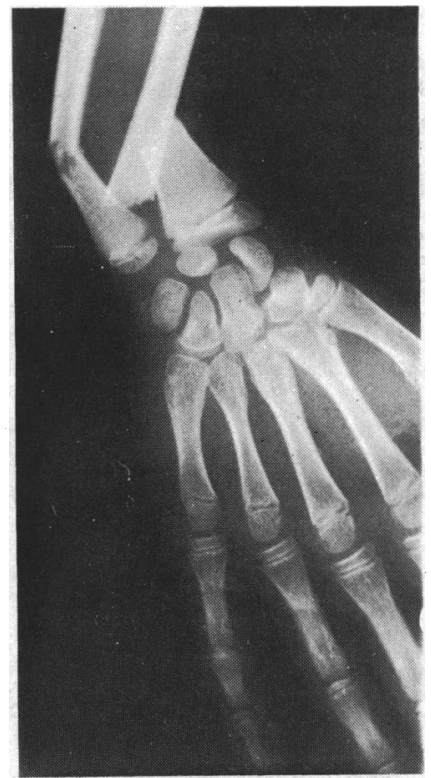

Fig. 3: The radiographs in Case 1. See text.

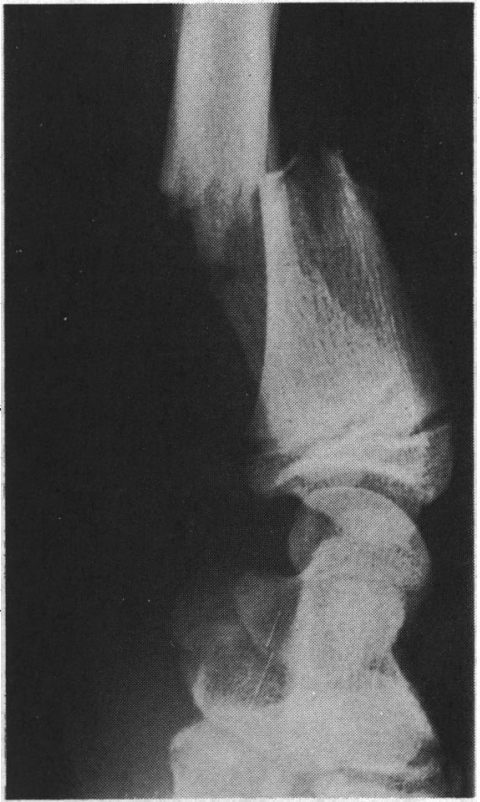

Fig. 4: The radiographs in Case 2. See text.

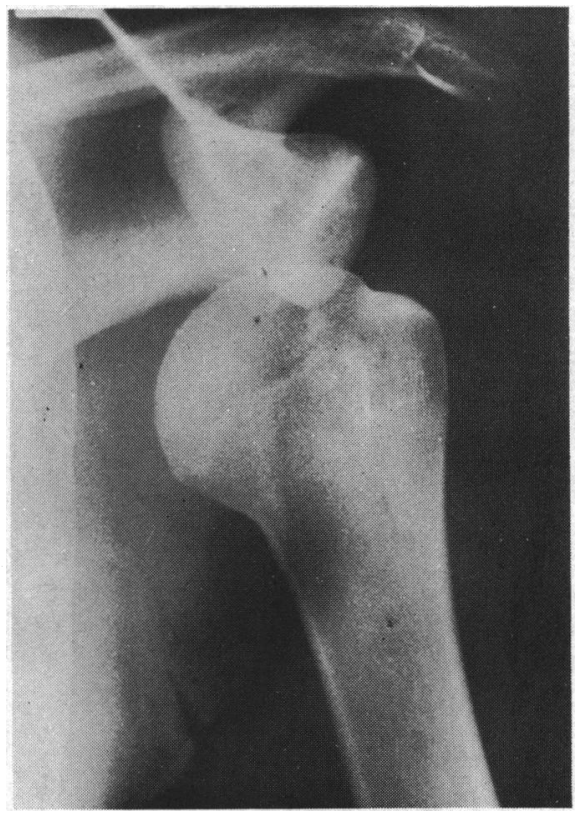

Fig. 5: The radiographs in Case 3. See text. 


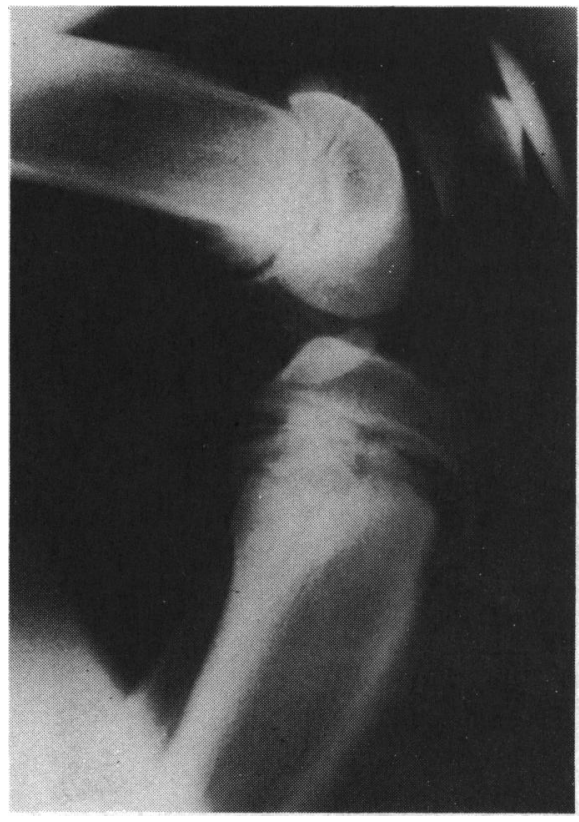

Fig. 6: The radiographs in Case 4 taken after the casualty officer tried closed reduction. See text.

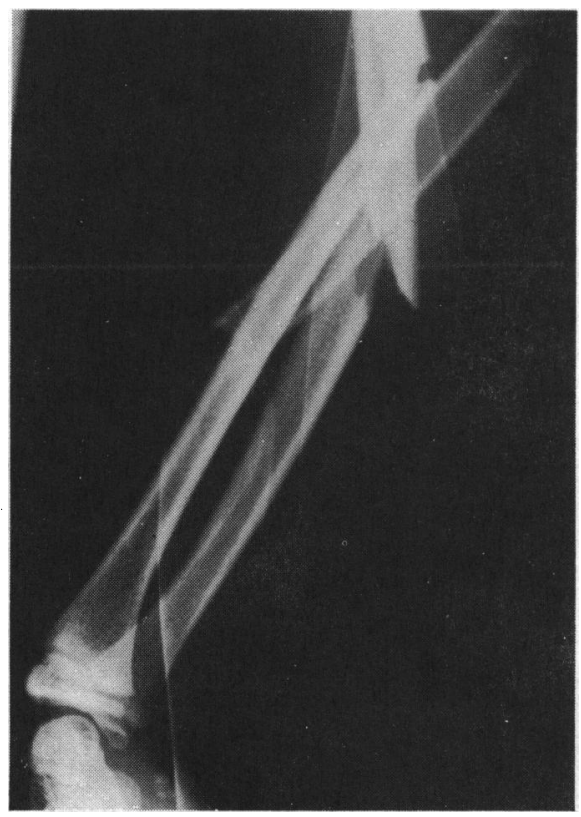

Fig. 7: The radiographs in Case 5. See text.

(30 $\mathrm{cm}$ thick) head first and was immediately tetraplegic due to dislocation of the fifth cervical vertebra on the sixth (Fig. 8). He noticed a temporary black-out on his way up from the mini trampoline. He was treated initially with closed reduction and skull traction for 12 weeks. Following traction there was spontaneous dislocation and a spondylodesis was performed. One year after the accident he remains incompletely tetraplegic. $\mathrm{He}$ is only able to walk 100 metres with two crutches and a splint on the left leg.

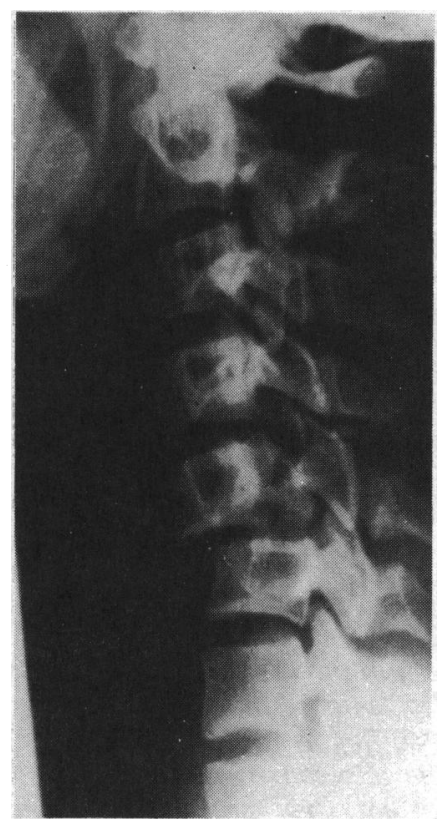

Fig. 8: The radiographs in Case 6. See text.

\section{COMMENT}

It is often argued that supervision and use of adequate safety precautions can prevent trampoline injuries.

The six patients presented here were all skilled trampolinists. Their specially qualified trampoline instructors were present, alert and unable to prevent the accidents. Three of the accidents occurred in physical education lessons in schools, while three occurred in clubs.

A preceding report in this Journal (Hammer et al, 1981 c) shows that supervision and safety precautions cannot prevent injuries. Well trained children were injured even from simple bounces at heights below one metre.

Another report concering 104 patients from various countries with severe neurological lesions - mostly tetraplegics - concludes that the presence of specially qualified instructors and helpers, and the best of mattresses is no guarantee against the neurological disaster (Hammer et al, 1981 a). 
The forces involved in trampolining are substantial. Therefore injuries of growing bones will often disturb growth and cause permanent damage. Among the 195 people re-examined in our preceding report 49 had after-effects and 44 of these were children (Hammer, 1981 c).

Ellis et al (1960) reported five cases (one died) who suffered severe neurological injuries from trampolining. We agree with one statement by Ellis et al (1960): "The most dangerous place on the trampoline remains the centre of the mat", but we disagree with their conclusions on minimum regulations concerning the use of trampolines. Our trampoline injuries could not have been avoided by minimum regulations, since they were actually not avoided even by the use of much more careful precautions, supervision and a maximum jumping height of one metre in the schools (Hammer et al, 1981 c).

Trampoline injuries are unnecessary injuries, especially since trampolining does not positively change the cardiorespiratory fitness as for example running does (Gabbard, 1980).

Trampolining may, even without accidents, lead to degenerative changes in the spine and cause lower back pain (Riehle, 1971).
This study and our previous reports (Hammer, Schwartzbach et al, 1981 a, b, c) shows that the large and the mini trampoline are posing an undue risk for severe injuries. Because of the risk for severe neurological injury the Danish Ministry of Education in 1981 advised the local authorities to stop trampolining in the Danish schools (Ministry of Education, Copenhagen, 1981).

We strongly support the statements taken by The American Academy of Pediatrics: "The trampolines should not be a part of routine physical education classes. The trampoline has no place in competitive sports. The trampoline should never be used in home or recreational settings" (American Academy of Pediatrics, 1981).

The National Board of Health has recommended the trampoline ban to be permanent in Danish schools and related public institutions (Natl. Board of Health, Copenhagen, 1981).

\section{ACKNOWLEDGEMENT}

Excellent assistance was provided by: Margit Hartyani, Hanne Østergaard, Maj-Britt Jellingdal and Raza Mallal.

\section{REFERENCES}

American Academy of Pediatrics, 1981 "Trampolines II". Pediatrics 67: 438.

Clarke, K. S., 1977 "A survey of sports-related spinal cord injuries in schools and colleges, 1973-1975". J.Safety Res. 9: $140-146$.

Ellis, W. G., Green, D., Holzaepfel, N. R. and Sahs, A. L., 1960 "The trampoline and serious neurological injuries". JAMA 174: 1673-1676.

Frykman, G. and Hilding, S., 1970 "Hopp pa studsmatta kan orseka allvarliga skador". Läkartidningen 67: 5862. 5864.

Gabbard, C., 1980 "Trampoline training and cardiorespiratory fitness among 8 and 9 year olds". J.Phys.Educ. 77: 94-95.

Hammer, A., Schwartzbach, A.-L., Darre, E. and Osgaard, O., 1981 a "Svaere neurologiske skader som følge af trampolinspring". Ugeskr. Laeg. 143 (45): 2970-2974.

Hammer, A., Schwartzbach, A.-L. and Paulev, P.-E., 1982 b "Children injured during physical education lessons - nine hundred and eighteen cases". J.Sports Med.Phys.Fit., Spring 82.

Hammer, A., Schwartzbach, A.-L. and Paulev, P.-E., 1981 c "Trampoline training injuries - one hundred and ninetyfive cases". Brit.J.Sports Med. 15: 151-158.

Ministry of Education. Copenhagen, 12th May, 1981 "Cirkulaereskrivelse om anvendelse af trampolinredskaber i tilknytning til folkeskolens idraetsundervisning". 
Rapp, G. F. and Nicely, P. G., 1980 "Trampoline injuries". Am.J.Sports Med., in press.

Riehle, H., 1971 “Über die Beanspruchung der Wirbelsäule beim Trampolinturnen". Diplomarbeit, Deutsche Sporthochschule, Köln.

Steinbrück, K. and Paeslack, V., 1978 "Trampolinspringen - ein gefährlicher Sport?". Münch.Med.Wschr. 129: 985-988.

The National Board of Health, Copenhagen, 26th November, 1981, Skrivelse No. 5542-1-1981.

\section{DIPLOMA IN SPORTS MEDICINE}

\section{OF}

THE LONDON HOSPITAL MEDICAL COLLEGE

(University of London)

It is anticipated that a Course leading to this College Diploma will start on October 5 th, 1982. It will last for three academic terms ( 24 weeks) and attendance will be required for at least 4 days per week.

The Course is intended for medically qualified personnel and aims to provide a sound theoretical and practical training for doctors responsible for the health and care of athletes engaged in all forms of sport. It should be understood that this does not constitute a training in orthopaedic surgery. The emphasis will be on providing an understanding of the scientific basis of factors important in fitness, effort, attitudes and stress. In the clinical field, instruction in the prevention, recognition, primary care and rehabilitation of sports injuries will be given. There will be a qualifying examination at the end of the third term.

It is intended that the Course should be residential (although this is not compulsory). Accommodation is available in the College Students' Hostel, but this is limited, and not appropriate for married couples. ${ }^{*}$ The rate is approximately $f 45$ per week which will include bed, breakfast and evening meal.

The Course will include visits to Sports Centres, Sports Injuries Clinics and other establishments to which transport costs are extra.

The fee for the Course is payable in advance and will be $£ 3,200$ for British and EEC graduates, and for others $£ 5,500$ which will be reduced to $£ 5,000$ if a deposit of $£ 500$ is made before the 31 st March, 1982 .

A copy of the programme for the Course will be available at its commencement.

Application forms and provisional timetables may be obtained from The Secretary to The Diploma Course in Sports Medicine, c/o The Surgical Unit, The London Hospital, Whitechapel, London E1 1BB.

\section{January 1982}

* The London University has some accommodation which is available to married couples, at a distance of about 5 miles from The London Hospital. 